\title{
GARAM GUNUNG ASAL KRAYAN SEBAGAI ZAT ADITIF UNTUK MENSTABILKAN KLOROFIL SAYURAN
}

\author{
Herman dan Laode Rijai \\ Fakultas Farmasi Universitas Mulawarman, Samarinda, Kalimantan Timur. \\ Email : herman.farmasi@yahoo.co.id
}

\begin{abstract}
ABSTRAK
Garam Gunung Asal Krayan yang terdapat pada wilayah utara pulau Kalimantan dipercaya oleh masyarakat setempat untuk menyembuhkan berbagai macam penyakit seperti darah tinggi, kencing manis, penyakit kulit serta beberapa penyakit lainnya. Sayur yang menggunakan garam gunung terlihat lebih segar atau nampak tidak layu dan kesegarannya tahan lama dibandingkan dengan menggunakan garam biasa. Dilakukan penelitian untuk mengetahui efek garam gunung asal Krayan terhadap stabilitas sayuran dilihat dari perubahan kadar klorofilnya dengan beberapa perlakuan. Klorofil diukur absorbannya dengan menggunakan spektrofotometer pada panjang gelombang $649 \mathrm{~nm}$ dan $665 \mathrm{~nm}$. Didapatkan hasil waktu penyimpanan sayuran yang menggunakan garam gunung asal Krayan yang masih mendekati klorofil sayuran segar adalah pada saat selesai pengolahan (0 jam) yaitu sebesar $22,11 \mathrm{ppm}$. Perubahan warna pada sayuran yang menggunakan garam gunung asal Krayan lebih lambat dibandingkan dengan garam biasa.
\end{abstract}

Kata Kunci : Garam gunung Krayan, sayuran, klorofil

\section{PENDAHULUAN}

Pulau Kalimantan adalah salah satu dari penghasil sumber daya alam yang berlimpah. Hasil sumber daya alam yang dihasilkan memilki keunikan tersendiri diantara wilayah yang satu dengan yang lainnya. Hasil alam yang unik itu salah satunya adalah Garam Gunung Asal Krayan yang terdapat pada wilayah utara pulau Kalimantan.

Garam gunung tersebut telah lama dimanfaatkan oleh masyarakat Krayan sebagai bahan tambahan dalam olahan makanan sehari-hari. Selain itu garam gunung tersebut dipercaya oleh masyarakat setempat untuk menyembuhkan berbagai macam penyakit seperti darah tinggi, kencing manis, penyakit kulit serta beberapa penyakit lainnya. Bahan baku garam gunung ini adalah air yang mengalir dari sumber air asin di anak sungai dan lereng bukit. Diduga air garam sebenarnya merupakan air laut yang terjebak dalam struktur lapisan geologi tertentu pada jutaan tahun yang lalu waktu daerah pegunungan Krayan adalah hamparan laut luas. Berdasarkan hasil observasi dengan masyarakat setempat, sayur yang diolah dengan menggunakan garam gunung berbeda dengan sayur yang diolah dengan garam yang dijual di pasaran, baik dari segi rasa maupun kualitas.

Sayur yang menggunakan garam gunung terasa lebih disukai dibandingkan dengan sayur yang dimasak menggunakan garam biasa. Demikian pula dari kesegarannya, sayur yang menggunakan garam gunung terlihat lebih segar atau nampak tidak layu dan kesegarannya tahan lama dibandingkan dengan menggunakan garam biasa yang 
dalam waktu beberapa jam sudah terlihat layu.

Sayuran memerlukan bahan yang dapat mempertahankan kesegarannya, salah satunya dengan bahan aditif. Aditif makanan adalah suatu substansi atau campuran substansi dari berbagai macam bahan makanan, yang ditambahkan dalam makanan untuk meningkatkan aspek produksi, pengolahan, penyimpanan dan pengemasan. Sejak jaman dahulu, bahan kimia telah ditambahkan pada makanan untuk meningkatkan beberapa fungsi. Meskipun ada makanan yang tidak menggunakan aditif, dalam proses untuk membuat makanan dalam berbagai variasi pada akhirnya akan tetap menggunakan aditif. Seiring dengan meningkatnya tekhnologi dalam pengolahan makanan maka meningkat pula jumlah aditif yang digunakan. Sekarang telah dikenal lebih dari 2500 aditif yang ditambahkan dalam produk makanan. Aditif dapat dibagi dalam 6 macam, antara lain; pengawet, nutrisi tambahan, flavoring agents, zat pewarna, texturing agents, dan aneka aditif lainnya (Salminen, 1990).

Mengetahui efek garam gunung asal Krayan terhadap stabilitas sayuran dilihat dari perubahan kadar klorofilnya dengan beberapa perlakuan

\section{METODE}

\section{Bahan.}

Bahan-bahan yang digunakan dalam penelitian ini antara lain garam gunung dari Krayan, Nunukan, kalium iodida, asam nitrat, kalium iodat, garam dapur, etanol dan aquades.
Alat

Alat yang digunakan antara lain spektrofotometer UV untuk mengukur absorbansi, lembar kuesioner (angket), alat sentrifugasi untuk memisahkan supernatan, serta peralatan laboratorium kaca yang mendukung.

\section{Penyiapan garam gunung dan garam dapur}

Garam gunung yang digunakan adalah garam yang berbentuk kristal-kristal garam yang diperoleh langsung dari Krayan kabupaten Nunukan. Sedangkan garam dapur yang digunakan diperoleh dari pasar tradisional.

\section{a. Perebusan sayuran}

Ditimbang daun bayam sebanyak $10 \mathrm{~g}$, aquades sebanyak $250 \mathrm{~mL}$. Dipanaskan aquades hingga mendidih dan ditambahkan 3 g garam biasa. Dimasukkan daun bayam dan biarkan selama 1 menit di dalam air mendidih dengan suhu didih $100{ }^{0} \mathrm{C}$. Dilakukan hal yang sama dengan mengganti garam biasa dengan Garam Gunung Asal Krayan.

\section{b. Analisis klorofil}

\section{Klorofil sayuran segar}

Ditimbang 0,1 g sampel sayuran segar, kemudian ditambahkan sedikit etanol sambil digerus dengan mortar. Dipindahkan kedalam labu ukur dan ditambahkan etanol hingga $10 \mathrm{~mL}$. Setelah itu dipindahkan dalam tabung sentrifus dan disentrifugasi dengan kecepatan $2000 \mathrm{rpm}$ selama 15 menit. Filtrat diambil dan diukur absorbannya dengan menggunakan spektrofotometer pada panjang gelombang 
$649 \mathrm{~nm}$ dan $665 \mathrm{~nm}$, etanol 96\% digunakan sebagai pembanding.

\section{Klorofil sayuran setelah penyimpanan 0 , 6, 12, 18 dan 24 jam}

Timbang 0,1 g sampel sayuran masak, kemudian ditambahkan sedikit etanol sambil digerus dengan mortar. Dipindahkan kedalam labu ukur dan ditambahkan etanol hingga $10 \mathrm{~mL}$. Setelah itu dipindahkan dalam tabung sentrifus dan disentrifugasi dengan kecepatan $2000 \mathrm{rpm}$ selama 15 menit. Filtrat diambil dan diukur absorbannya dengan menggunakan spektrofotometer pada panjang gelombang $649 \mathrm{~nm}$ dan $665 \mathrm{~nm}$, etanol 96\% digunakan sebagai pembanding.

\section{HASIL DAN PEMBAHASAN}

Untuk mengetahui perubahan kadar Klorofil terhadap sampel maka didalam penelitian ini dilakukan pengujian dengan mengukur kadar Klorofil pada sayuran yang menggunakan garam gunung dan garam biasa. Dalam mengukur kosentrasi Klorofil ada beberapa metode, salah satunya dengan mengekstraksi Klorofil dengan menggunakan etanol dan diukur absorbansinya menggunakan spektroskopi UV-Vis. Keunggulan dari metode ini adalah sederhana, mudah, dan cepat. Dalam aspek kuantitatif, suatu berkas radiasi dikenakan pada larutan sampel dan intensitas sinar radiasi yang yang diteruskan diukur besarnya. Radiasi yang diserap oleh larutan sampel ditentukan dengan membandingkan intensitas sinar yang diteruskan dengan intensitas sinar yang diserap jika tidak ada spesies penyerap lainnya. Klorofil larut dalam etanol dan akan membentuk larutan klorofil-etanol yang menyerap cahaya pada panjang gelombang tertentu.
Hasil pengujian perbedaan klorofil antara sayuran yang menggunakan garam gunung asal Krayan dengan garam biasa dapat dilihat dari tabel 1 .

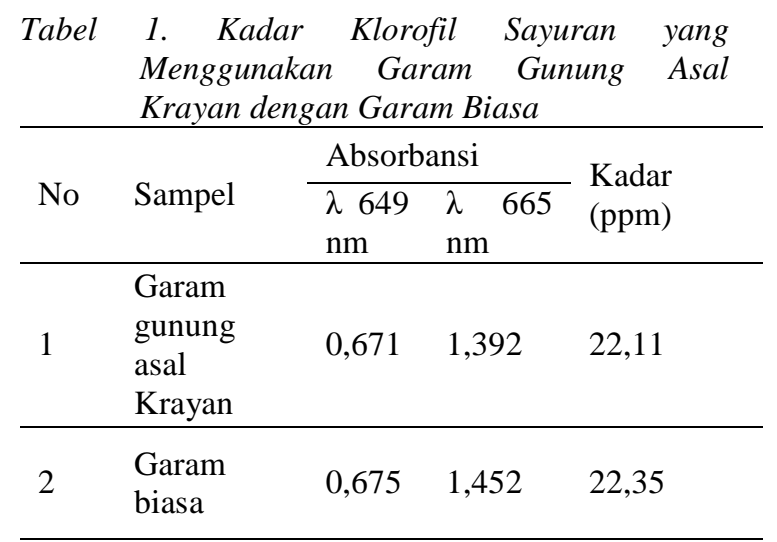

Berdasarkan Tabel 1. dapat dilihat bahwa tidak terdapat perbedaan jumlah klorofil antara sayuran yang menggunakan Garam Gunung Asal Krayan dengan sayuran yang menggunakan garam biasa.

\section{Perubahan Kadar Klorofil Sayuran Berdasarkan Lama Penyimpanan}

Pada pengujian untuk mengetahui pengaruh waktu terhadap perubahan kadar klorofil sayuran yang menggunakan garam gunung, terlebih dahulu dilakukan perebusan sayuran yaitu dengan merebus $50 \mathrm{~g}$ sayur bayam didalam $250 \mathrm{~mL}$ aquades mendidih dan ditambahkan $3 \mathrm{~g}$ garam. Sayuran yang telah dimasak kemudian disimpan dan diukur kadar klorofilnya pada waktu 0 jam, 6 jam, 12 jam, 18 jam dan 24 jam. Dari sayuran yang telah disimpan tersebut diambil $0,1 \mathrm{~g}$ daun kemudian ditambahkan sedikit etanol sambil digerus dengan mortar untuk menghaluskan daun sampel agar mudah terekstraksi. Sampel dipindahkan kedalam labu takar dan ditambahkan etanol hingga $10 \mathrm{~mL}$. Sampel kemudian disentrifus untuk memisahkan partikel kasar yang tidak terlarut yang akan mengganggu 
pengukuran. Masing-masing perlakuan dilakukan sebanyak 3 replikasi.

Hasil pengujian pengaruh waktu penyimpanan terhadap kadar klorofil sayuran yang menggunakan garam gunung asal Krayan dapat dilihat dari Tabel 2 dan Tabel 3.

\begin{tabular}{|c|c|c|c|c|}
\hline$T a b$ & $\begin{array}{c}\text { Pengaru } \\
\text { Peruba } \\
\text { Menggu } \\
\text { Krayan }\end{array}$ & $\begin{array}{rr} & W c \\
\text { nKadar } & K \\
\text { kan } \quad G a\end{array}$ & rofil Sa & $\begin{array}{l}\text { Terhadap } \\
\text { uran yang } \\
\text { ung Asal }\end{array}$ \\
\hline \multirow[b]{2}{*}{ No } & \multirow{2}{*}{$\begin{array}{l}\text { Waktu } \\
\text { (jam) }\end{array}$} & \multicolumn{2}{|l|}{ Absorbansi } & \multirow{2}{*}{$\begin{array}{l}\text { Kosentrasi } \\
(\mathrm{ppm})\end{array}$} \\
\hline & & $\lambda 649 \mathrm{~nm}$ & $\begin{array}{ll}\lambda & 665 \\
\mathrm{~nm} & \\
\end{array}$ & \\
\hline 1 & 0 & 0,671 & 1,392 & 22,11 \\
\hline 2 & 6 & 0,585 & 1,182 & 18,91 \\
\hline 3 & 12 & 0,569 & 1,201 & 18,70 \\
\hline 4 & 18 & 0,545 & 1,173 & 18,05 \\
\hline 5 & 24 & 0,463 & 1,016 & 15,73 \\
\hline
\end{tabular}

Tabel 3. Anava Pengaruh Waktu Terhadap Perubahan Kadar Klorofil Sayuran yang Menggunakan Garam Gunung Asal Krayan

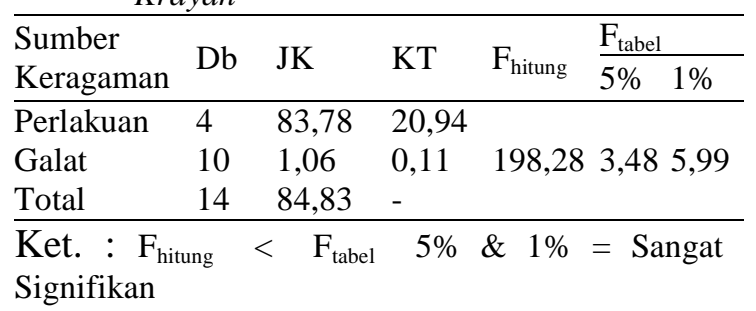

Dari Tabel 3 menunjukkan bahwa dari hasil analisis varian diperoleh nilai $F$ hitung sebesar 198,28. Nilai F hitung yang diperoleh lebih besar dari nilai $\mathrm{F}$ tabel $5 \%$ maupun $1 \%$ yaitu 3,48 dan 5,99 . Hal ini berarti kadar klorofil yang terdapat dalam sampel mengalami penurunan kadar yang signifikan seiring berjalannya waktu. Ada beberapa hal yang berpengaruh dalam berkurangnya kadar klorofil. Klorofil mudah larut dalam air sehingga dalam proses penyimpanan klorofil akan terekstraksi kedalam air dan kadar klorofil dalam daun berkurang.

\section{Waktu Penyimpanan Yang Mendekati Klorofil Sayuran Segar}

Pada pengujian untuk mengetahui waktu penyimpanan sayuran yang dimasak dengan garam gunung asal Krayan yang masih memenuhi klorofil yang mendekati klorofil sayuran segar, terlebih dahulu dilakukan perebusan sayuran yaitu dengan merebus $50 \mathrm{~g}$ sayur bayam didalam 250 $\mathrm{mL}$ aquades mendidih dan ditambahkan 3 g garam. Sayuran yang telah dimasak kemudian disimpan dan diukur kadar klorofilnya pada waktu 0 jam, 6 jam, 12 jam, 18 jam dan 24 jam. Dari sayuran yang telah disimpan tersebut diambil $0,1 \mathrm{~g}$ daun kemudian ditambahkan sedikit etanol sambil digerus dengan mortar untuk menghaluskan daun sampel agar mudah terekstraksi. Sampel dipindahkan kedalam labu takar dan ditambahkan etanol hingga $10 \mathrm{~mL}$.

Sampel kemudian disentrifus untuk memisahkan partikel kasar yang tidak terlarut yang akan mengganggu pengukuran. Sedangkan untuk klorofil sayuran segar diambil 0,1 g daun segar tanpa dimasak kemudian ditambahkan sedikit etanol sambil digerus dengan mortar untuk menghaluskan daun sampel agar mudah terekstraksi. Sampel dipindahkan ke dalam labu takar dan ditambahkan etanol hingga $10 \mathrm{~mL}$. Sampel kemudian disentrifus untuk memisahkan partikel kasar yang tidak terlarut yang akan mengganggu pengukuran Masing-masing perlakuan dilakukan sebanyak 3 replikasi.

Hasil pengujian waktu penyimpanan sayuran yang dimasak dengan garam gunung asal Krayan yang masih memenuhi 
klorofil yang mendekati klorofil sayuran segar dilihat dari tabel 4.

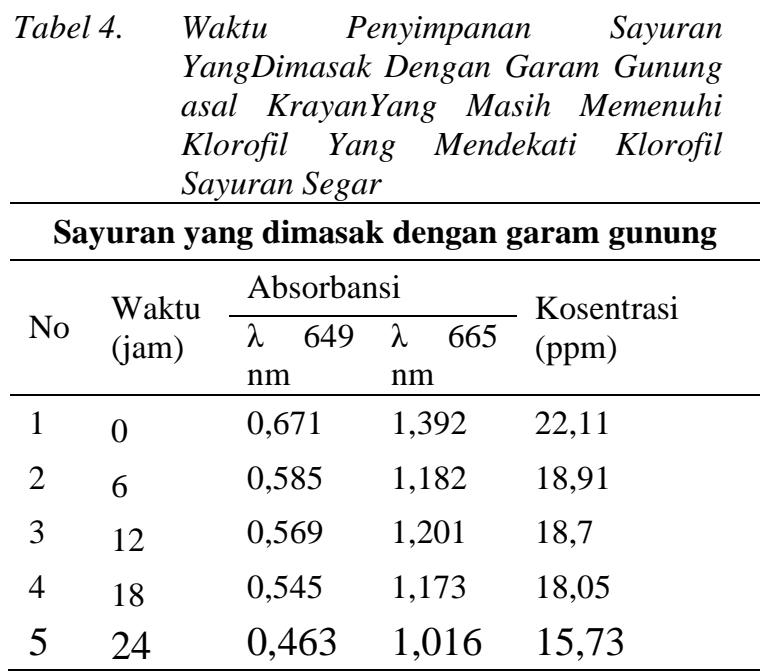

Tabel 5. Hasil pengukuran klorofil sayuran segar

\begin{tabular}{|c|c|c|c|c|}
\hline \multicolumn{5}{|c|}{ Sayuran segar } \\
\hline \multirow[b]{2}{*}{ No } & \multirow{2}{*}{$\begin{array}{l}\text { Waktu } \\
\text { (jam) }\end{array}$} & \multicolumn{2}{|c|}{ Absorbansi } & \multirow{2}{*}{$\begin{array}{l}\text { Kosentrasi } \\
(\mathrm{ppm})\end{array}$} \\
\hline & & $\begin{array}{ll}\lambda & 649 \\
\mathrm{~nm}\end{array}$ & $\begin{array}{ll}\lambda & 665 \\
\mathrm{~nm}\end{array}$ & \\
\hline 1 & 0 & 0,71 & 1,485 & 23,25 \\
\hline
\end{tabular}

Berdasarkan Tabel 4 dan 5 dapat dilihat bahwa kadar klorofil yang paling mendekati klorofil sayuran segar adalah waktu penyimpanan 0 jam yaitu pada saat sayuran baru selesai dimasak. Lamanya waktu penyimpanan dapat mempengaruhi kadar klorofil yang terdapat didalam sayuran, dikarenakan beberapa hal seperti yang dijelaskan pada percobaan sebelumnya. Klorofil adalah pigmen karena menyerap cahaya. Cahaya sangat bepengaruh dalam perubahan kadar klorofil dalam sampel, dengan adanyanya cahaya maka akan mengubah struktur dari klorofil. Selain itu klorofil mudah larut dalam air sehingga dalam proses penyimpanan klorofil akan terekstraksi ke dalam air dan kadar klorofil dalam daun berkurang.

\section{KESIMPULAN}

Dari hasil penelitian yang telah dilakukan dapat disimpulkan sebagai berikut:

1. Waktu penyimpanan sayuran yang menggunakan garam gunung asal Krayan yang masih mendekati klorofil sayuran segar adalah pada saat selesai pengolahan (0 jam) yaitu sebesar 22,11 ppm.

2. Perubahan warna pada sayuran yang menggunakan garam gunung asal Krayan lebih lambat dibandingkan dengan garam biasa.

3. Garam gunung asal Krayan dapat mempertahankan kestabilan klorofil sayuran dibandingkan garam dapur biasa.

\section{DAFTAR PUSTAKA}

1. Badan Standardisasi Nasional, 2010. Garam Konsumsi Beryodium. SNI 3556:2010.

2. Association of Offical Analytical Chemistry. 2005. AOAC Official Method 999.11

3. Lead, Cadmium, Copper, Iron, and Zinc, 18th Edition, Chapter 9.1.09

4. Association of Offical Analytical Chemistry. 2005. AOAC Official Method 971.21 Mercury in Foods, Atomic Absorption Spectrophotometric method, Chapter 9.2.22 